\title{
Effect of laser radiation on catalytic properties of silicon electrodes covered with a transition metal film and providing water decomposition
}

\author{
V.E. Primachenko, L.L. Fedorenko, Yu.A. Tsyrkunov, S.A. Zinio, S.I. Kirillova, \\ V.A. Chernobai, E.F. Venger \\ V. Lashkaryov Institute of Semiconductor Physics, NAS of Ukraine \\ 41, prospect Nauky,03028 Kyiv, Ukraine \\ E-mail:pve18@isp.kiev.ua
}

\begin{abstract}
Current creation caused by water decomposition $\mathrm{H}_{2} \mathrm{O} \rightarrow \mathrm{OH}+\mathrm{H}$ has been investigated for the case of an $\mathrm{Yb}$-Si electrode pair after the preliminary covering of $\mathrm{Si}$ electrodes with transition metal ( $\mathrm{Ni}, \mathrm{Ti}, \mathrm{Cr}$ ) films, as well as exposing them to laser radiation. It has been shown that laser radiation, as a rule, increases the efficiency of current creation owing to the improvement of electrode catalytic properties as to water decomposition. We observed also some change in the electron work function for these electrodes.
\end{abstract}

Keywords: water decomposition, current creation, electron work function.

Manuscript received 23.05.07; accepted for publication 27.09.07; published online 22.10.07.

\section{Introduction}

Current creation between two electrodes with different electron work functions (with different electrochemical potentials) dipped into distilled water is a natural source to extract energy [1-4]. This phenomenon is caused by water decomposition $\mathrm{H}_{2} \mathrm{O} \rightarrow \mathrm{H}^{+}+\mathrm{OH}^{-}$as a consequence of the catalytic action of electrodes and the availability of a potential difference between them, which is supported by the energy releasing at the electrodes due to the discharge of $\mathrm{H}^{+}$and $\mathrm{OH}^{-}$ions.

In works [1-4], we studied various electrodes with the aim to obtain the most efficient current creation in electrochemical systems. In particular, we found the metal silicides to be rather promising as cathodes [4]. This finding, to some extent, stimulated us to perform this work, where we use $n$-Si electrodes (as cathodes) covered with films of transition metals $(\mathrm{Ni}, \mathrm{Ti}, \mathrm{Cr})$ and then irradiated with pulses of an YAG: $\mathrm{Nd}^{3+}$ laser. As known [5], when the metal film - silicon structure is irradiated with a laser, one can observe the "mixing" of a metal and silicon and the formation of a new film phase on the silicon surface with a developed relief which consists of metal silicides or a metal-silicon eutectic. Such surface phase can essentially change the water decomposition process on it. The present work is devoted to this subject.

\section{Experimental}

As the initial samples, we chose the $n$-Si ones with the resistivity $4 \mathrm{Ohm} \cdot \mathrm{cm}$ and dimensions $20 \times 10 \times 0.5 \mathrm{~mm}$, whose surface being polished chemically and mechanically. Thermal vacuum deposition was used to cover them with a film of one of the chosen transition metals (Ni, Ti, Cr), the film thickness being about $100 \mathrm{~nm}$. To provide a good adhesion of these metal films, the silicon substrate was heated up to $T \approx 300{ }^{\circ} \mathrm{C}$ in the case of $\mathrm{Ni}$ and $\mathrm{Ti}$, while heating was not used in the course of $\mathrm{Cr}$ deposition.

In the electrochemical cell, we used distilled water, ytterbium as an anode, and the sample of silicon with a deposited metal film as a cathode. To preliminarily determine the electron work function for these siliconmetal electrodes, we used the pair of electrodes $\mathrm{Si}\langle\mathrm{Me}\rangle$ Pt where the Pt plate played the role of a cathode and the $\mathrm{Si}\langle\mathrm{Me}\rangle$ electrode did that of an anode. The electron work function $\varphi$ for the $\mathrm{Si}\langle\mathrm{Me}\rangle$ electrode was determined using the method offered in [1-4] and based on the measurements of currents between $\mathrm{Pt}$ and $\mathrm{Si}\langle\mathrm{Me}\rangle$ electrodes in forward and backward directions when applying the voltage $V= \pm 9.7 \mathrm{~V}$ to the electrodes. The choice of the Pt electrode is related to its anticorrosion resistance and the relative stability of its electron work function $(5.32 \mathrm{eV})$. 
Experimentally investigated were the time dependences of the current $J(t)$ between the electrodes $\mathrm{Yb}$ and $\mathrm{Si}\langle\mathrm{Me}\rangle$ at various states of the $\mathrm{Si}\langle\mathrm{Me}\rangle$ electrode surface, namely: before the laser exposure, after the action of YAG: $\mathrm{Nd}^{3+}$ laser pulses $(\lambda=1.06 \mu \mathrm{m}, \tau=$ $150 \mu \mathrm{s})$ in the free generation mode when the energy of pulses reached $P=7.5 \mathrm{~J} / \mathrm{cm}^{2}$ (destruction threshold for $\mathrm{Si})$ as well as after increasing the pulse energy up to 1.5P. As usual, we used the front irradiation (from the side of the metal film), but sometimes we did the rear one (from the side of $\mathrm{Si}$ ) with account of $\mathrm{Si}$ transparency at $\lambda=1.06 \mu \mathrm{m}$.

Dipping both electrodes into water was made simultaneously. First, we measured the arising potential difference between them, $\Delta V_{k}$, (it is less in its magnitude than the difference $\Delta \varphi$ ), then we made the external circuit to close $(t=0)$ and measured the current $J(t)$ by using a microamperemeter. With regard for possible variations of the $\mathrm{Si}\langle\mathrm{Me}\rangle$ electrode area $S$ and the distance $L$ to the $\mathrm{Yb}$ electrode as well as variations of $\Delta V_{k}$ for different $\mathrm{Si}\langle\mathrm{Me}\rangle$ electrodes possessing also a different catalytic activity in water decomposition, we calculated the specific conductivity of this electrochemical system to provide an objective estimation of current creation

$\sigma_{s p}=\left(L / \Delta V_{k} S\right) J(t)=A J(t)$,

where the coefficient $A=L / \Delta V_{k} S \mathrm{~V}^{-1} \mathrm{~cm}^{-1}$.

Therefore, for the sake of illustration, we plotted the dependences $A J(t)$. In the cases where the external voltage $V= \pm 9.7 \mathrm{~V}$ was applied to the electrodes, one should change $\Delta V_{k}$ for $\Delta V_{k} \pm V$ when calculating $\sigma_{s p}$.

\section{Results and discussion}

In Fig. 1, curves 1, 2, and 3 show the $A J(t)$ dependences obtained without any external voltage applied to the electrodes $(V=0)$ for the pairs $\mathrm{Yb}-n-\mathrm{Si}, \mathrm{Yb}-\mathrm{Si}\langle\mathrm{Ni}\rangle($ after the laser irradiation with power $P)$ and $\mathrm{Yb}-\mathrm{Si}\langle\mathrm{Ni}\rangle(1.5 P)$. It is well seen that the values of $A J(t)$ for the electrodes with the Ni film are higher than those without it and have a tendency to increase with the power of laser irradiation of $\mathrm{Si}\langle\mathrm{Ni}\rangle$ electrodes. This growth of $A J(t)$ cannot be explained by changes in the electron work function $\varphi$ for the electrodes under study (see Table) as the changes of $\varphi$ are less than $8 \%$.

This growth in $A J(t)$ after the laser-induced "mixing" of the Ni layer with silicon is caused by an increase of the electrode catalytic activity in water decomposition as a consequence of changes in the structure and composition of its surface. This "mixing" is accompanied with the creation of silicides with various compositions, and the surface structure becomes more inhomogeneous in its relief [5]. Both of these factors can increase the electrode catalytic activity in water decomposition. Moreover, the values of $A J(t)$ are higher within the time interval $0<t<10$ min when the voltage $\Delta V_{k}$ between the $\mathrm{Yb}-\mathrm{Si}\langle\mathrm{Ni}\rangle$ electrodes is

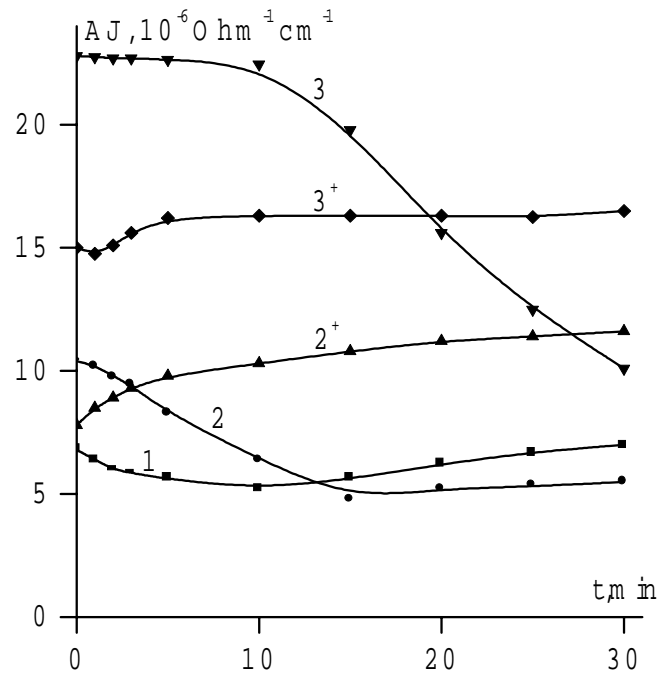

Fig. 1. Time dependences of the conductivity $A J(t)$ of the system $\mathrm{YbSi}\langle\mathrm{Ni}\rangle$ in distilled water. 1 - conductivity of the $\mathrm{Yb}-\mathrm{n}-\mathrm{Si}$ system without any external voltage on it $(V=0)$ after irradiation of $\mathrm{n}-\mathrm{Si}$ with the threshold laser radiation $P ; 2$, $2^{+}-$conductivities of the $\mathrm{Yb}-\mathrm{Si}\langle\mathrm{Ni}\rangle$ system after laser radiation $P$ action at $V=0$ and $V=+9.7 \mathrm{~V}$ on the $\mathrm{Yb}$ electrode, respectively; $3,3^{+}-$conductivity of the $\mathrm{Yb}-\mathrm{Si}\langle\mathrm{Ni}\rangle$ system after action of $1.5 P$ laser radiation (at $V=0$ and $V=$ $=+9.7 \mathrm{~V}$ on the $\mathrm{Yb}$ electrode, respectively).

somewhat higher than that at $t \approx 30 \mathrm{~min}$. But, however, it cannot manage with the fast separation of $\mathrm{H}^{+}$and $\mathrm{OH}^{-}$ ions created due to the catalysis at the $\mathrm{Si}\langle\mathrm{Ni}\rangle$ electrode. It is also confirmed by dependences $2^{+}$and $3^{+}$obtained when applying the additional voltage $V=+9.7 \mathrm{~V}$ to the $\mathrm{Yb}$ electrode in the external circuit. The character of dependences $2^{+}$and $3^{+}$differs from that of dependences 2 and 3. Owing to the fast separation of ions by the voltage $V=+9.7 \mathrm{~V}$, the values of $A J(t)$ for curves $2^{+}$and $3^{+}$near the point $t=0$ are less than the respective values for curves 2 and 3 , although the values of $A J(t)$ for curves $2^{+}$and $3^{+}$become higher with time $(t>$ 2...20 $\mathrm{min})$.

Some distinctive values of $A J(t)$ were obtained for the pair of electrodes $\mathrm{Yb}$-Si $\langle\mathrm{Ti}\rangle$ (Fig. 2). Curves 1, 2, and 3 describe the dependences $A J(t)$ obtained at $V=0$ for the electrode pairs before the laser irradiation of the $\mathrm{Si}\langle\mathrm{Ti}\rangle$ electrode and after the irradiation with pulses having the power $P$ and $1.5 P$, respectively. Changes of $\varphi$ for the electrode were negligible in this case (see Table), and the growth of $A J(t)$ for curves 1 to 3 is caused, like to the $\mathrm{Si}\langle\mathrm{Ni}\rangle$ electrode case, by increasing the catalytic efficiency of water decomposition after the laser-induced "mixing" of the Ti film with silicon.

By applying the additional voltage $V=+9.7 \mathrm{~V}$ to the $\mathrm{Yb}$ electrode in the external circuit, we obtained the respective dependences $1^{+}, 2^{+}$, and $3^{+}$. It is worth to note that, contrary to the $\mathrm{Si}\langle\mathrm{Ni}\rangle$ electrode, the values of $A J(t)$ for the $\mathrm{Si}\langle\mathrm{Ti}\rangle$ electrode (curves $1^{+}, 2^{+}$, and $3^{+}$) were always higher than those for curves 1,2 and 3 . On the one hand, this is caused by the less catalytic activity of 
Table.

\begin{tabular}{|l|c|}
\hline \multicolumn{1}{|c|}{ State of the electrode surface } & $\begin{array}{c}\text { Electron work } \\
\text { function, } \mathrm{eV}\end{array}$ \\
\hline Real surface of $n$-Si & 4.91 \\
Real surface of $n$-Si after laser & 4.68 \\
irradiation (power $P$ ) & 4.98 \\
\hline Electrode $\mathrm{Si}\langle\mathrm{Ni}\rangle$ & 4.82 \\
Electrode $\mathrm{Si}\langle\mathrm{Ni}\rangle$ after laser irradiation \\
(power $P$ ) & 4.94 \\
Electrode $\mathrm{Si}\langle\mathrm{Ni}\rangle$ after laser irradiation \\
(power $1.5 P$ ) Electrode $\mathrm{Si}\langle\mathrm{Ni}\rangle$ after rear \\
(from the silicon side) laser irradiation \\
$(1.5 P$ )
\end{tabular}

the $\mathrm{Si}\langle\mathrm{Ti}\rangle$ electrode as compared with that of the $\mathrm{Si}\langle\mathrm{Ni}\rangle$ one. On the other hand, this is related with the faster separation of $\mathrm{H}^{+}$and $\mathrm{OH}^{-}$ions at the $\mathrm{Si}\langle\mathrm{Ti}\rangle$ electrode, which can be caused by different structural features of surface films after the laser irradiation of these two electrodes. High, increasing with time values of $A J(t)$ in curves $1^{+}, 2^{+}, 3^{+}$as compared with those in curves 1,2 and 3 for the $\mathrm{Si}\langle\mathrm{Ti}\rangle$ electrode are indicative of an essential role played by the electric field at protrusions of the electrode surface to accelerate the catalytic process [4].

The dependences $A J(t)$ for the electrode pair $\mathrm{Yb}$ $\mathrm{Si}\langle\mathrm{Cr}\rangle$ are plotted in Fig. 3. It is seen that the efficiency of current creation at $V=0$ considerably grows after the irradiation of the $\mathrm{Si}\langle\mathrm{Cr}\rangle$ electrode with laser pulses of the power $P$ (curves 1 and 2). However, the further increase in the power up to $1.5 P$ results in decreasing the values of $A J(t)$ (curve 3). Obviously, it is related to the fact that the $\mathrm{Cr}$ film was deposited onto the Si substrate at room temperature, which did not provide its sufficient adhesion to the substrate, and, with increase in the laser pulse power, the $\mathrm{Cr}$ film escapes from the $\mathrm{Si}$ substrate. Dependences $2^{+}$and $3^{+}$(Fig. 3) obtained with the additional potential $V=+9.7 \mathrm{~V}$ on the $\mathrm{Yb}$ electrode, like to the case of the $\mathrm{Yb}-\mathrm{Si}\langle\mathrm{Ni}\rangle$ and $\mathrm{Yb}-\mathrm{Si}\langle\mathrm{Ti}\rangle$ pairs, are indicative of an essential role of the electric field near protrusions of the $\mathrm{Si}\langle\mathrm{Cr}\rangle$ electrode surface relief in the catalytic process.

The results of the laser irradiation $(1.5 P)$ from the side of $\mathrm{Si}$ are shown as the dependences $A J(t)$ at $V=0$ in Fig. 4 for the pairs $\mathrm{Yb}-\mathrm{Si}\langle\mathrm{Ti}\rangle$ (curve 1) and $\mathrm{Yb}-\mathrm{Si}\langle\mathrm{Ni}\rangle$ (curve 2). From comparison of these data with the similar ones (curves 3, Figs 1 and 2), it follows: (i) to

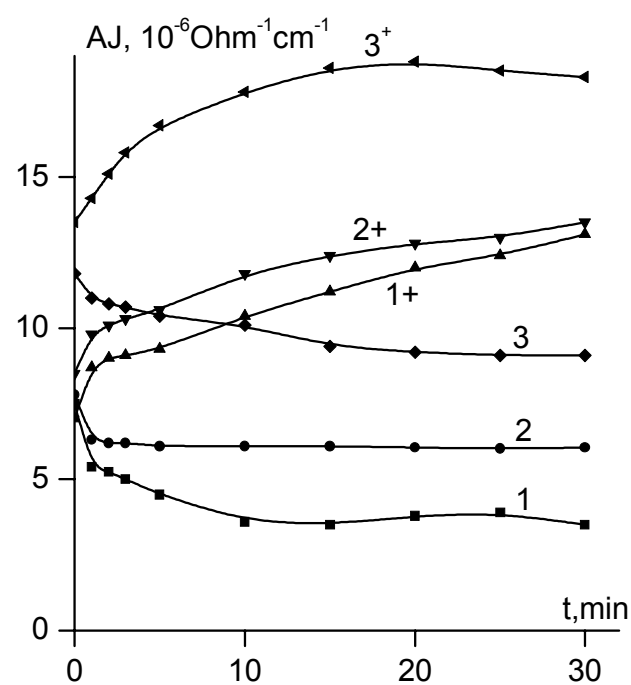

Fig. 2. $A J(t)$ dependences for the system $\mathrm{Yb}-\mathrm{Si}\langle\mathrm{Ti}\rangle .1,1^{+}-$ before laser action on $\mathrm{Si}\langle\mathrm{Ti}\rangle$ (at $V=0$ and $V=+9.7 \mathrm{~V}$ on the $\mathrm{Yb}$ electrode, respectively); 2, $2^{+}-$after laser action with the power $P$ (at $V=0$ and $V=+9.7 \mathrm{~V}$ on the $\mathrm{Yb}$ electrode, respectively); $3,3^{+}-$after laser irradiation with the power $1.5 P$ (at $V=0$ and $V=+9.7 \mathrm{~V}$ on the $\mathrm{Yb}$ electrode, respectively).

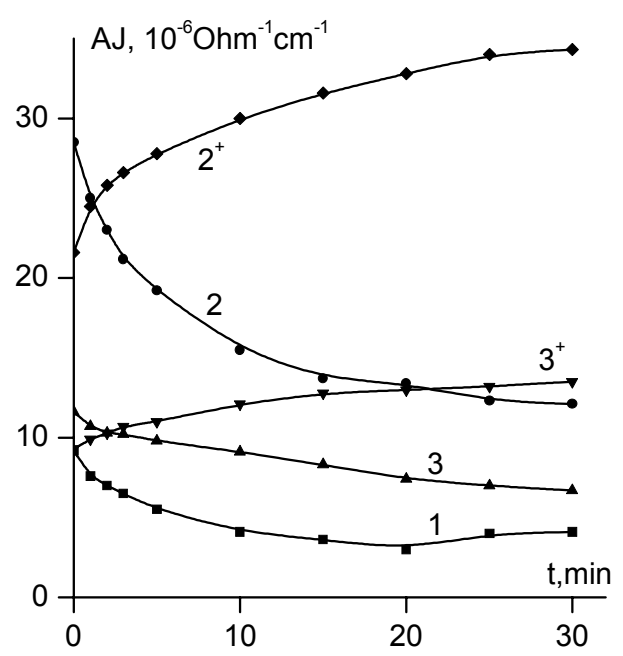

Fig. 3. $A J(t)$ dependences for the system $\mathrm{Yb}-\mathrm{Si}\langle\mathrm{Cr}\rangle .1-$ before laser irradiation (at $V=0) ; 2,2^{+}$- after laser action with the power $P$ on the $\mathrm{Si}\langle\mathrm{Cr}\rangle$ electrode (at $V=0$ and $V=$ $+9.7 \mathrm{~V}$ on the $\mathrm{Yb}$ electrode, respectively); $3,3^{+}-$after laser irradiation with the power $1.5 P$ (at $V=0$ and $V=+9.7 \mathrm{~V}$ on the $\mathrm{Yb}$ electrode, respectively).

obtain higher values of $A J(t)$, the irradiation from the side of a metal is more efficient for the "mixing" of a metal with silicon; (ii) when irradiating from the rear (silicon) side, the dependences $A J(t)$ near $t=0$ have a considerable "fast" ( $4 \mathrm{~min})$ part of decreased $A J(t)$ values, which is alien to the dependences $A J(t)$ when irradiating from the side of a metal. The latter fact is indicative of different structures of the mixed Me-Si film for these two ways of illumination. 


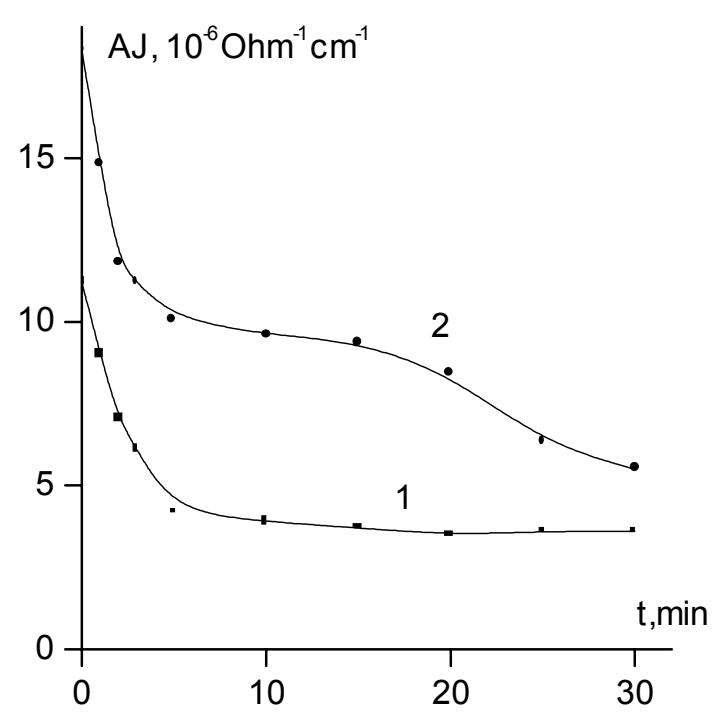

Fig. 4. $A J(t)$ dependences for the systems $\mathrm{Yb}-\mathrm{Si}\langle\mathrm{Ti}\rangle(1)$ and $\mathrm{Yb}-\mathrm{Si}\langle\mathrm{Ni}\rangle(2)$ at $V=0$ after laser irradiation with the power $1.5 P$ of the electrodes $\mathrm{Si}\langle\mathrm{Ti}\rangle$ and $\mathrm{Si}\langle\mathrm{Ni}\rangle$ form the rear (silicon) side.

\section{Conclusions}

1. Laser-induced "mixing" of the film of transition metals $(\mathrm{Ni}, \mathrm{Ti}, \mathrm{Cr})$ with a silicon substrate changes the electron work function for the $\mathrm{Si}\langle\mathrm{Me}\rangle$ electrode only a little $(<8 \%)$.

2. The several-time growth of the process providing the current creation between the electrodes $\mathrm{Yb}$ $\mathrm{Si}\langle\mathrm{Me}\rangle$ without applying the external voltage to them $(V=0)$ is caused by the increasing catalytic activity of $\mathrm{Si}\langle\mathrm{Me}\rangle$ electrodes after the laser-induced "mixing" of the film of transition metals with silicon.
3. The growth of the conductivity between the $\mathrm{Yb}$ $\mathrm{Si}\langle\mathrm{Me}\rangle$ electrodes when applying the additional voltage $(V=+9.7 \mathrm{~V})$ to $\mathrm{Yb}$ is related to the increasing catalytic activity of $\mathrm{Si}\langle\mathrm{Me}\rangle$ electrodes due to the enhancement of local electric fields at structural inhomogeneities inherent to $\mathrm{Si}\langle\mathrm{Me}\rangle$ electrodes.

4. To obtain the more efficient current creation at $\mathrm{Si}\langle\mathrm{Me}\rangle$ electrodes, the preliminary laser irradiation of these electrodes should be performed from the side of the metal film, and its deposition before that should be carried out onto the heated $\left(300^{\circ} \mathrm{C}\right)$ silicon substrate to provide the good adhesion between a metal and silicon.

\section{References}

1. V.E. Primachenko, B.M. Bulach, S.I. Kirillova, V.A. Chernobai, E.F. Venger, Electronic properties of palladium-doped porous silicon and its application for water decomposition without applying electric voltage // Ukr. J. Phys. 52(3), p. 237-244 (2007).

2. V.E. Primachenko, S.I. Kirillova, I.V. Kud', V.A. Chernobai, Decomposition of water under application of electrodes with catalytic properties // Zhurnal Tekhnicheskoi Fiziki, to be published (2007) (in Russian).

3. V.E. Primachenko, A.A. Serba, V.A. Chernobai, E.F. Venger, Influence of oxidation of catalytically active silicon-based electrodes on water decomposition // Semiconductor Physics, Quantum Electronics and Optoelectronics 9(1), p. 88-96 (2007).

4. V.E. Primachenko, A.A. Serba, V.A. Chernobai, E.F. Venger, Influence of some physico-chemical factors on electrode properties by catalytic water decomposition // Semiconductor Physics, Quantum Electronics and Optoelectronics 9(2), p. 40-45 (2007).

5. J.S. Williams, J.M. Poote, Ion Implantation and Beam Processing. Academic Press, New York, 1984. 